\title{
State of Developing Mobility as a Service in the City of Zagreb
}

\author{
Marko SLAVULJ, Dubravko TOMAŠIĆ, Mario ĆOSIĆ, Dino ŠOJAT
}

\begin{abstract}
Mobility as a Service (MaaS) is a paradigm for shifting from private cars to different mobility solutions encompassing every transport mode in the form of a service consumed according to passenger needs. As well as Smart City and Smart Mobility, this is a relatively new concept that has become possible due to recent developments in information and communication technologies and intelligent transport systems, and it is most feasible in dense urban environments, where demands for mobility are the highest. This paper will present an overview of current trends of MaaS in the world as well as state in the City of Zagreb, providing the most prominent areas for MaaS as well as the most probable obstacles. This paper will also present an approach to solutions for implementation in Croatian cities by the best recommendations and examples of good practice analysed.
\end{abstract}

Keywords: city of Zagreb; mobility as a service; smart city; smart mobility; urban transport

\section{INTRODUCTION}

The ever-increasing global urbanisation trends in the past decades resulted in higher demands for mobility, and therefore, high private car usage, which led to traffic congestion in most cities in the world. This trend will only increase, as it is predicted by the United Nations that $68 \%$ of the world population will live in urban areas by 2050 , and 55\% lived in urban areas in 2018 [1]. Therefore, managing transport demand becomes a more complex and challenging task for traffic experts. The build-only approach could not solve this issue, so new ways of thinking became mandatory to improve urban mobility. The results of these new approaches should be indicated in cities by less space consumption, less energy consumption and less environmental issues.

A Smart City is an urban area using information and communication technologies, business models, and solutions to increase operational efficiency, share information with the public and improve both the quality of services and citizen welfare. The Smart Mobility is one of the important pillars of the Smart City-it refers to using various technology solutions in every field of transport and traffic science, increasing the possibilities for implementing technology into transport sector. The development of information and communication technologies is the key factor for creating a Smart City and Smart Mobility. The goal of Smart City and Smart Mobility is to optimize travel time, reduce usage of space, private cars, road accidents and preventing harmful gas emissions as well.

Mobility as a Service (MaaS) is a relatively new concept, which holds the promise for a paradigm shift in the provision of urban mobility-its concept mainly refers to using a single app to access and pay for various transport modes within a city or beyond, such that the app gives options to allow a traveller to select the most suitable transport mode and most suitable price plan, thus removing the problems related to planning and one-off payments [2, 3].

The measurement of the state of mobility is a rather complex topic. Firstly, this is because there are uncertainties in what should be measured-mobility only, sustainability of mobility, "smartness" of a city, "smartness" of mobility, or the level of mobility services.
Usually, the measurements are represented as indicators, which can enable cities to benchmark against each other. These indicators can be concrete, such as operating speed, travel time, travel distance (considering relationships between peak and off-peak periods), generalised costs and elasticity when considering transport demand; and less concrete, such as legal documents related to sustainability, quality of public area, comfort, or functional diversity. For measuring these indicators, there are several methodologies. One of them is created by the Arthur D Little Consultancy [4], named Urban Mobility Index 2.0, which puts the cities on a scale from zero to hundred points based on criteria related to maturity and performance, mostly compared to city population. If measuring the performance of public transport only, useful can be methodologies such as The World Bank [5], where the indicators are both qualitative and quantitative, and can be derived from user opinion. Specifically, the indicators can be used to put the sustainability of mobility in question, such as in Sustainable Mobility Project 2.0 [6], or by the Institute for Transportation \& Development Policy [7].

The goal of this paper is to present the concept of Mobility as a Service, its framework, current developments and trends, conditions that must be made in order to further expand it, as well as major obstacles that could threaten its growth from local to global scale. Also, the paper will present current state of Mobility as a Service in the City of Zagreb, giving insight into problems related to Zagreb as well as the recommendations to integrate the existing services. With the vision of MaaS as an effective way to address urban mobility problems, the purpose of these goals is to accelerate the efforts for making the City of Zagreb a MaaS-driven city.

The paper consists of five chapters. After the introduction of the terminology in Chapter 1, Chapter 2 presents the developments of Mobility as a Service in the world. Chapter 3 will focus on analysing the state of MaaS in the City of Zagreb, stating the problems. These chapters are followed by the discussion and conclusion.

\section{CURRENT DEVELOPMENTS AND TRENDS OF MOBILITY AS A SERVICE}

The European Commission has an agenda on making the transport systems of the future more reliable, 
sustainable, and attractive to users. It encourages and stimulates administrations on local, regional and national level to accept the long-term integrated transport policy, necessary in the complex European environment. The following documents are fundamental for developing smart mobility in the European Union: White Paper 2001 [8], Green paper 2007 [9]; Action Plan on Urban Mobility 2009 [10] and White Paper 2011 [11]. These documents can be considered as the legal framework which encouraged new ways of thinking regarding urban mobility, eventually resulting in the European Union as a MaaS pioneer.

Mobility as a Service has been theoretically discussed in an UITP position paper in 2011, in which an association of public transport operators predicted combining different transport modes, such as car sharing, taxi, bike sharing, car pooling and demand-responsible transport into a single service, opening the possibilities for urban mobility to become more flexible [12]. In practice, the concept of MaaS probably started to evolve "by accident"-on monthly or yearly subscriptions of public transport (metro, bus, train), which is already a common practice in many cities, even with combining different service providers, because sometimes it was convenient for the services to be extended onto bicycle rentals or taxis, in order to be convenient for public transport users. Therefore, other modes become integrated, so that the users did not have to worry about additional costs. In previous years, this kind of integration was seen in mobile communications, when the price of a phone call was made the same whatever the network operator. The concept of MaaS has also become possible in recent times because of the developments in information technologies, and different mobility providers, such as car sharing, bike sharing, have also become feasible. In addition, changes in lifestyles of younger generations and people who choose to live in cities rather than the traditionally suburban lifestyle made the private car less desirable, giving clear path for the alternatives. Further development of technologies is already observable, because of technology improvements such as using smartphones to unlock the shared bicycle or to prove the validity of their public transport tickets to ticket control personnel.

In defining the framework of Mobility as a Service, a proposal of three main elements that provide users with seamless intermodal journeys was made [13, 14]. These elements are:

- Ticket \& Payment integration: when one smart card or ticket can be used to access all the modes taking part in the service and one account is charged for the use of those services.

- Mobility package: when customers can pre-pay for a specific amount (in time or distance) of a combination of mobility services.

- ICT integration: when there is a single application or online interface that can be used to access information about the modes.

Similar to the elements stated above, Jittrapirom et al (2017) determined nine core characteristics of MaaS based on the current literature: Integration of every transport mode, tariff option, one-platform functionality, multiple actors, use of technologies, demand orientation, registration requirement, personalisation, and customisation [15]. Szmelter (2018) defined the functionalities of IT solutions for MaaS based on predefined areas: service design, technology design, organization design and finance design [16].

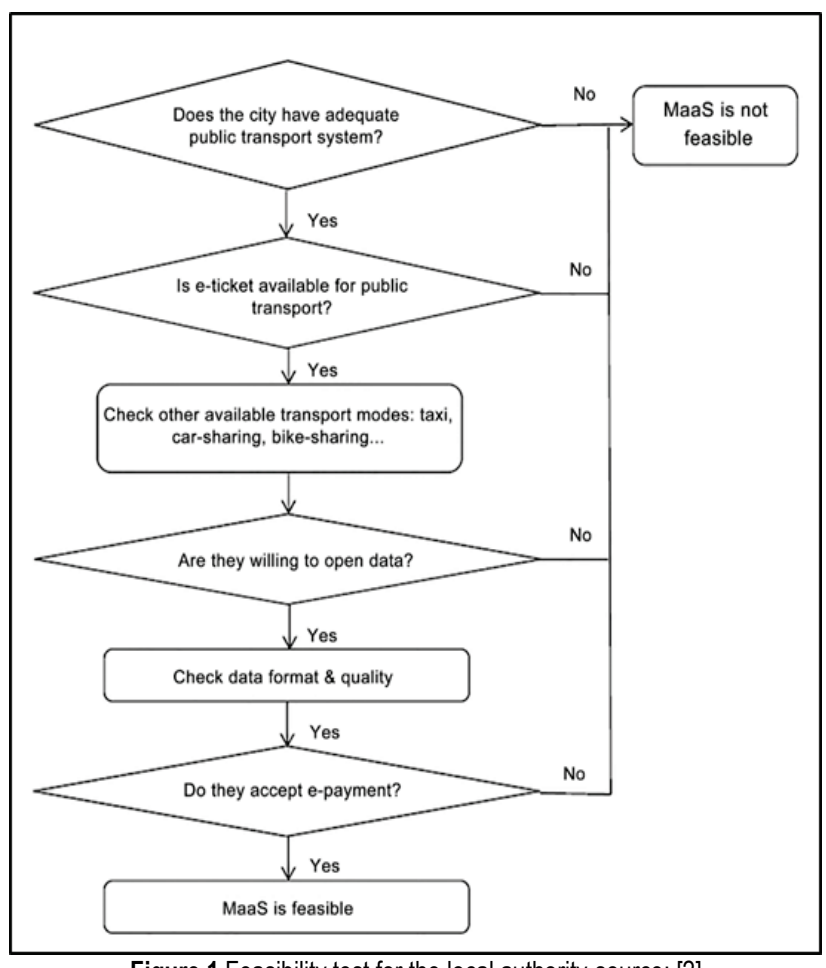

Figure 1 Feasibility test for the local authority-source: [2]

To be able to implement MaaS as a feasible solution in a city, there are several preconditions to be made, and they have to be timely aligned, as shown in Fig. 1 in form of flow-chart test [2]. First, the public transport system must be adequate, with e-ticketing implemented. The following precondition refers to all other mobility service providers and their willingness to provide their mobility statistics. The last precondition is related to integration of e-payment services. Therefore, the city authority, as a legal body, must determine a sound traffic policy with sustainability as a goal even before taking MaaS into consideration.

Although MaaS can be developed in rural areas, the most prominent areas for developing MaaS are denselypacked urban areas, where there is the highest potential in transport demand for adopting it quickly and effectively [17]. To help the local authorities assess the readiness for adopting MaaS, indicators such as in the CIVITAS ECCENTRIC project (2016-2020) can be used [18].

Although MaaS is most commonly observed from the perspective of service providers, IT technologies or local authority, less effort is being put into end-user perspective. Lyons et al (2019) observed user need and proposed a MaaS behavioural schema to illustrate potential consideration and adoption of MaaS from the user perspective [19], suggesting that a strong need exists for market research to better understand MaaS user attitudes, needs and choice making behaviour, because otherwise, the enthusiastic drive to deliver MaaS may falter or face unanticipated challenges that could have been foreseen and accounted for. This scheme is shown in Fig. 2. 


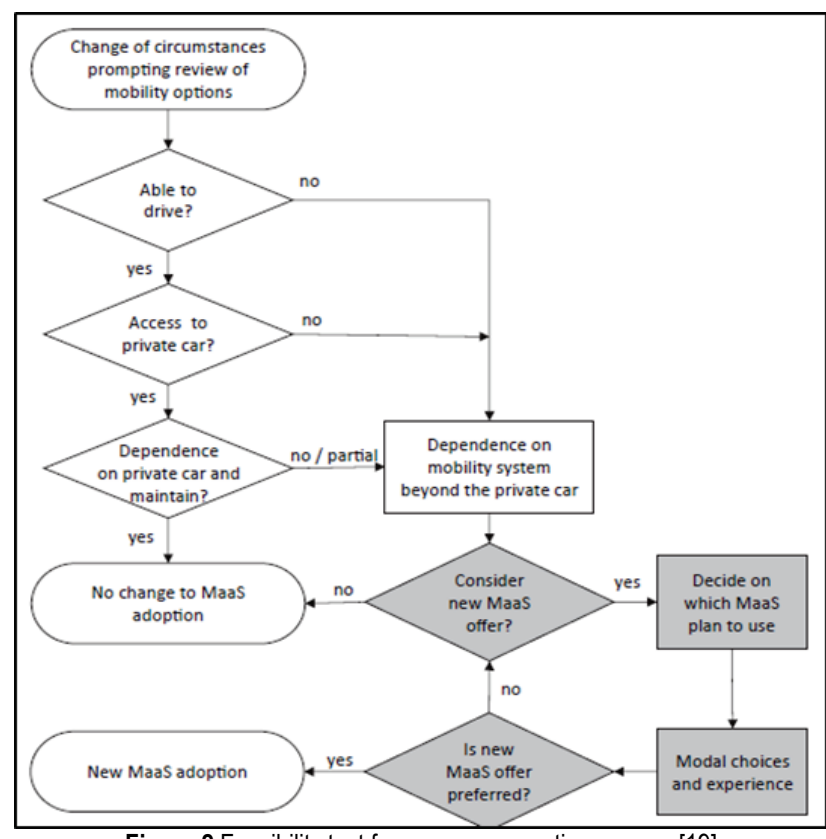

Figure 2 Feasibility test from user perspective-source: [19]

One of the most active cities in Europe, a global testing ground in promoting MaaS, is Helsinki in Finland, with population of 1.4 million. The company MaaS Global crated a start-up smartphone app called Whim [20], in which urban travellers in Helsinki can plan and pay for trips, choosing between public transport, bike-sharing, taxis and car-sharing through single payments or subscriptions (Fig. 3). The Whim app is considered as the first MaaS solution for smartphones in the world. Although the best advocate for such applications are national and local governments, according to the experience, it is not clear how effective Maas can be if public transport authorities in European cities do not want to see these thirdparty platforms succeed. Considering public transport authorities as major obstacles, companies to improve MaaS started emerging, such as Masabi [21] for integrating mobile ticketing services, SkedGo [22] for implementing MaaS solutions into start-ups, corporations and governments, and Moovel [23], which provides mobility apps in German cities and mobile ticketing apps in North America.

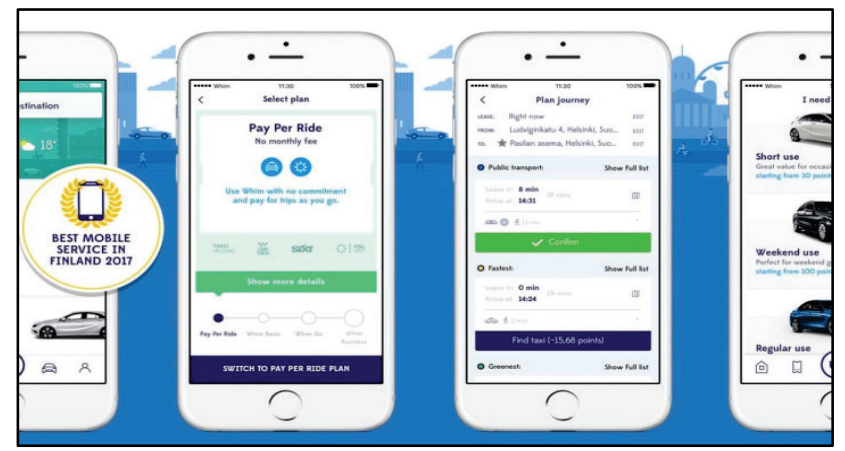

Figure 3 Smartphone application "Whim" in Helsinki, Finland-source: [24]

The value of MaaS market can be expected to reach a quarter trillion USD by 2023 [25]. The major companies aiming to share these profits are BMW Group (Germany), Alliance Corporation (Canada), Apple Inc. (U.S), Xerox Corporation (U.S.), Lyft, Inc. (U.S), Uber Technologies Inc. (U.S.), MaaS Global (Finland), Deutsche Bahn
(Germany), Daimler AG (Germany), and Communauto (Canada). In Europe, there is a significant growth registering, with Germany, Finland, U.K., and France as top leaders. It is predicted that the revenues from MaaS will exceed one trillion USD by 2030 [26].

As of today, MaaS operates mostly at a local level. But considering the development of MaaS in the future, there is a forecast that the same MaaS app will be possible to use when travelling in different cities, like what has Uber done for taxi services. To help further development, the MaaS Alliance has been created in 2015, a public-private partnership aimed to further develop MaaS in Europe and beyond [27]. In the transnational research programme by the European Directors of Roads (CEDR), a project named Mobility as a Service for Linking Europe (MAASiFiE) was established precisely for investigating prerequisites for organizing new mobility services. There were four potential MaaS operator models identified-Reseller, Integrator, Public transport operator and public-private partnership. To help develop MaaS services, corresponding regulatory framework and new ways of collaboration at international level are necessary [28]. Smith et al (2018) interviewed 19 MaaS actors active in West Sweden to see how MaaS could be developed and how public transport could be affected. Three predictive scenarios were identified-market-driven, public-controlled and public-private, suggesting that finding a regulatory "sweet spot" that drives innovation and secures public benefits will be key for future developments [29].

Although MaaS is considered as the most promising solution to tackle urban mobility problems, there are several issues potentially to be addressed, as stated in Giesecke et al. (2016): nature of travel, interoperability with intelligent transport services, end-user perspective and sustainability [30]. Even in Europe, a proving ground for MaaS, a unique platform could face fierce competition from the existing travel apps offering global services. Mobility as a Service can also pose a major challenge for IT sector, especially in the period of shared economy, where the emphasis is put onto services and users independent of a private car.

\section{STATE OF MOBILITY AS A SERVICE IN THE CITY OF ZAGREB}

The City of Zagreb is the capital and the largest city in Croatia, with the area of $641 \mathrm{~km}^{2}$, estimated population of 0,8 million, and 1,2 million in the urban agglomeration. The data regarding the City of Zagreb related to mobility are mostly provided from the traffic study done in 1999, which is an outdated reference, if compared with the present state. Although at that point there was no standardization of indicators, data collection and data processing, there were data on: average travel time in the city 27 minutes, average trip length 8 kilometres, and 2,7 trips per day and person. The motorisation rate was a moderate 440 vehicles per 1000 inhabitants, as this was the period when the purchasing power started to rise in the country. According to the analysis done within the FP7 CIVITAS-ELAN project for the City of Zagreb in 2009 [31], motorization rate was at its highest ever, and the trips split into private car $32 \%$, public transport $34 \%$, and walking and cycling 34\%. Despite the positive trend in 
sustainable modes, the number of trips by private cars causes traffic congestion in the City on a high scale in peak periods, although the motorization rate of the country in 2016 (374 vehicles per 1000 inhabitants according to Eurostat), is still a moderate one, if compared to the other European countries [32].

The current state of mobility in the City of Zagreb and the Republic of Croatia was analysed by Brčić et al (2018) through the Smart City and Smart Mobility paradigms [33], concluding that there is a potential for further development of smart cities and smart mobility as an integrated part of a smart city part, stating opportunities for MaaS to develop, based on the current EU agenda and the legal framework.

Mass public transport in the city is provided by the local transport authority-Zagreb Electric Tram (ZET), with 19 tram lines in the urban area and 150 bus lines operating in urban as well as suburban areas, transporting 290 million passengers a year [34]. The operating speed in tram transport is between 13 and $14 \mathrm{~km} / \mathrm{h}$, and it is significantly lower than the average values in the similar EU cities. Nevertheless, the state of transport demand indicates that there is a need for introducing light-rail or metro into the public transport network. The existing public transport network lacks priority at intersections and segregation from other traffic to make it faster and reducing its costs. The costs of ZET are subsidized in about $70 \%$ rate by the City and the remainder by ticket sales, which is one of the most heavily subsidized schemes in Europe. By using twolevel evaluation, Matulin et al (2011) assessed public transport in the city, concluding that the absence of a highquality service management is the main reason of poor network performance mostly related to public transport priority at signalized intersections, with consequent unreliable journey plans for passengers [35]. Šipuš et al. (2018) presented the literature review on tariffs in integrated passenger transport systems, stating the necessity to plan tariff systems objectively in the context of eliminating transport disadvantage and maximizing social equity [36]. This is especially considerable for the City of Zagreb, since there was an integrated ticket pricing in tram and railway transport in the City, currently discontinued due to disagreements between Zagreb Electric Tram and Croatian Railways.

There are currently nine providers in the City of Zagreb that contribute to mobility (Fig. 4):

- Nextbike, a bike-sharing service.

Spin City, a car-sharing service.

HŽPP, Croatian Railways Passenger Transport, who established an app for tracking train positions.

Uber, CarGo and Bolt (former Taxify) for providing taxi services.

Zagreb Electric Tram, for providing public transport services (tram and bus).

ZgPark and WePark, for providing parking services.

By observing the existing state, it can be concluded that the City of Zagreb offers a variety of services, covering everything from cycling to rail. The citizens can even benefit from the fact that there is a car-sharing service and a bike-sharing service. However, all these services, besides mass public transport by tram, bus and rail, are in their early stages regarding the extent of integration. None of these services is integrated into a common platform, so daily commuters must have several types of services (each of them with its own application) to be able to use each transport mode, and visitors would rather give up on using the service if the complexity exceeds the single-fare ticket (except for Uber which has become a standard in many cities). Additionally, the financial models in these emerging providers (mostly no subsidies from the City) suggest a poor service-although the Nextbike service has bicycle terminals in key areas of the City, the number of terminals is insufficient for a widespread use; and although Spin City provides a car sharing service (even by electric cars), there are limitations regarding the areas where the vehicles can operate, or the number of vehicles themselves. All these facts do not encourage majority of users to register for any of the services.

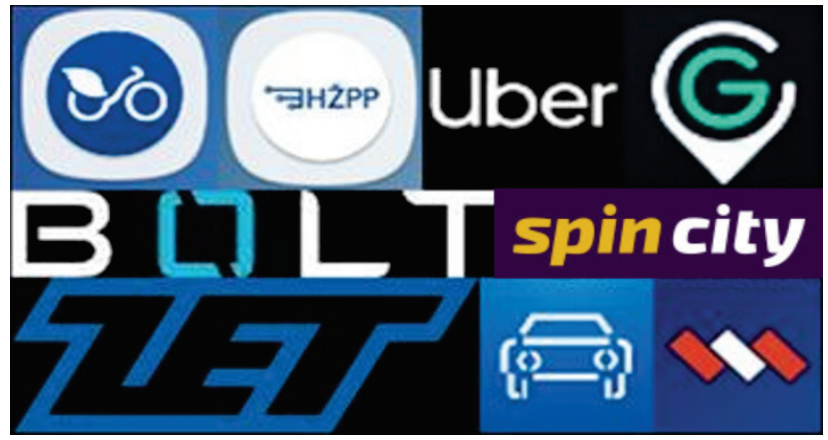

Figure 4 Mobility service providers in the City of Zagreb - source: authors

In addition to the lack of integration of mobility services mentioned above, there is also a lack of integration in the transport system itself. The possibility of introducing a traffic control centre in the City of Zagreb was discussed in the last two decades, but the actual centre is a matter of foreseeable future. Until the introduction, the existing traffic modes, traffic light control and car park management system will have to operate to an acceptable level of synchronization.

\section{DISCUSSION}

To evaluate MaaS, there are two preconditions to fulfil. First is a unified methodology and its set of indicators-there are four sound methodologies stated in this paper, each with specific area of mobility and specific set of indicators; however, a standardized methodology and a set of indicators is necessary, to successfully evaluate the state and the progress of MaaS. The second is a wellestablished protocol for monitoring these indicators directly in the user application. This would require a standard application, and this requires further development of ICT technology and integration.

A typical MaaS application requires users to go through an initial registration process to be able to use the service. The consequence of this is many electronic identities on the web for just one person. This can be very confusing and frustrating for the users, especially if they must remember a username and a password for each identity. Besides mobility, this is a common issue for every type of online service. Google and Facebook partially resolved this problem by establishing OAuth protocols for using their identities for a third-party service. There is also an initiative called OpenID Connect, to create an open and decentralized authentication protocol. However, until 
today, there is not a single type of e-identity accepted, as this is hard to achieve on even EU scale. This potential eidentity could be based on personal identification in the country of residence, and instead of many identities today, this identity would only be granted access to services requested by the person. This would also prevent the problems with false identities, but also pose a great security risk, so great efforts would have to be made in information technologies to make it entirely safe to use. There would have to be a global institution involved (such as United Nations) for making this idea possible to implement on a global scale.

The central point of MaaS is a single application that unifies every transport mode into a single service, so the focus is on getting from origin to destination as practically and conveniently possible, and this is used as the main argument for attracting people to use the service. However, there is less effort put into researching the psychological aspect of MaaS-to research true human needs that could be provided by mobility. Mobility as a Service has a potential and should be used as a tool to improve physical and psychological health of users.

Despite different business models proposed, implementing and operating a MaaS service requires a single identity for a user, open data and open payment methods from various transport modes. If a transport operator is not willing to use a third-party payment to buy its tickets or to not allow third party to sell its tickets on their behalf, services of the transport operators cannot be included in MaaS. In many countries public transport tickets have been heavily regulated and no third party can sell tickets rather than the operator itself. Within such legal framework, integrated ticketing of various modes may not be possible, rendering MaaS unfeasible. Considering that public transport authority is subsidized by local authority, this can prove advantageous or disadvantageous, depending on subsidies and the will to improve the current state.

The urban transport in the City of Zagreb is characterized by insufficient data on indicators and lack of standardized methodology for the indicators, regarding data collection and the body responsible for such a task. Public transport has a low operating speed, so public transport priority has to be introduced to improve the attractiveness of public transport, since it is the backbone of MaaS. Based on the current transport demand, there is a need for a system of greater capacity, such as light-rail, to be introduced soon. The excessive private car usage, together with traffic user behaviour, suggests implementing a sustainable urban mobility plan with initiatives for using sustainable modes of transport to rationalize transport in terms of space, environment, energy consumption and costs.

\section{CONCLUSIONS}

Mobility as a Service represents a promising solution to all problems related to mobility today-low level of integration from traffic and logistics perspective, and poor variety of mobility services. In the world, the current trends will place MaaS as significant part of consumer services. However, if there is a will for MaaS to become commonplace, there are certain obstacles that must be crossed:

- lack of initiative to make global universal e-identities based on personal identity in the country of residence (on EU level or higher),

- lack of the unified methodology for benchmarking mobility in general and specifically MaaS in urban environments,

- lack of understanding user behaviour in traffic and lack of understanding real human needs that can be satisfied in the field of mobility,

- problems related to the most suitable logistic models and business models to help developing MaaS as fast as possible.

As for the City of Zagreb and its integration into the future vision of the European Union regarding Mobility as a Service, there are several problems that firstly must be solved in order for the City to become a feasible ground for implementing MaaS:

- inefficient public transport system regarding operating speed and capacity,

- modal split in favour of private car suggests problems related to traffic user behaviour,

- lack of a unified and comprehensive mobility database as well as non-transparent data, especially by public transport operator.

These problems can be solved with putting most efforts on the decision-making level into a sound traffic policy based on the current EU legal framework, with documents such as master plan and sustainable urban mobility plan as the guidelines for the development in the short and long-term. Mobility as a Service should be considered as a main tool for promoting urban trips beneficial for both users and the community.

\section{REFERENCES}

[1] United Nations Department of Economic and Social Affairs. (2018, 5 16). $68 \%$ of the world population projected to live in urban areas by 2050, says UN. Retrieved from https://www.un.org/development/desa/en/news/population/ 2018-revision-of-world-urbanization-prospects.html (March 19, 2019)

[2] Li, Y. \& Voege, T. (2017). Mobility as a Service (MaaS): Challenges of Implementation and Policy Required. Journal of Transportation Technologies, 7, 95-106. https://doi.org/10.4236/jtts.2017.72007

[3] Connecting Cambridgeshire. (n.d.). Smart Travel - Mobility as a Service (MaaS). Retrieved from https://www.connectingcambridgeshire.co.uk/SMARTPLACES/SMART-CAMBRIDGE/MOBILITY-AS-ASERVICE/ (March 19, 2019)

[4] Van Audenhove, F. J., Korniichuk, O., Dauby, L., \& Pourbaix, J. (2014). The Future of Urban Mobility 2.0. Arthur D Little.

[5] Henning, T., Essakali, M. D., \& Oh, J. E. (2011). A Framework for Urban Transport Benchmarking. Washington DC: The International Bank for Reconstruction and DEvelopment / The World Bank.

[6] Oran Consulting. (2015). Sustainable Mobility Project 2.0. Geneva: World Business Council for Sustainable Development. Retrieved from https://docs.wbcsd.org/2015/03/Mobility_indicators.pdf

[7] Institute for Transportation \& Development Policy. (n.d.). Indicators for Sustainable Mobility. Retrieved from 
itdp.org/publication/indicators-sustainable-mobility (04-022019)

[8] European Commission. (2001, September 12). White paperEuropean transport policy for 2010: time to decide. Retrieved from ec.europa.eu/transport/sites/transport/files/ themes/strategies/doc/2001_white_paper/lb_com_2001_03 70_en.pdf (April 8, 2019)

[9] European Commission. (2007, May 25). Green Paper Towards a new culture for urban mobility. Retrieved from eur-lex.europa.eu/legal-content/EN/TXT/PDF/?uri= CELEX:52007DC0551\&from=EN (April 8, 2019)

[10] European Commission. (2009, September 30). Action Plan on Urban Mobility. Retrieved from eur-lex.europa.eu/legalcontent/EN/TXT/PDF/?uri=CELEX:52009DC0490\&from= EN (April 8, 2019)

[11] European Commission. (2011, March 28). White paper 2011. Retrieved from eur-lex.europa.eu/legalcontent/EN/TXT/PDF/?uri=CELEX:52011DC0144\&from= EN (April 8, 2019)

[12] UITP-International Association of Public Transport. (2011). Becoming a Real Mobility Provider Combined Mobility: Public Transport in Synergy with Other Modes Like CarSharing, Taxi and Cycling. Retrieved from https://www.uitp.org/sites/default/files/cck-focus-papersfiles/FPComMob-en.pdf (March 19, 2019)

[13] Motta, G., Ferrara, A., Sacco, D., You, L., \& Cugola, G. (2013). Integrated Mobility: A Research in Progress. Journal of Software Engineering and Applications, 6, 97-101. https://doi.org/10.4236/jsea.2013.63B021

[14] Schade, W., Krail, M., \& Kühn, A. (2014). New mobility concepts: myth or emerging reality? Transport Research Arena 2014 (TRA 2014). Paris

[15] Jittrapirom, P., Caiati, V., Feneri, A.-M., Ebrahimigharehbaghi, S., Alonso-González, M. J., \& Narayan, J. (2017). Mobility as a Service: A Critical Review of Definitions, Assessments of Schemes, and Key Challenges. Urban Planning, 2(2), 13-25. https://doi.org/10.17645/up.v2i2.931

[16] Szmelter, A. (2018). Mobililty-as-a-Service - A Challenge fot IT in the age of sharing economy. Information Systems in Management, 7(1), 59-71. https://doi.org/10.22630/ISIM.2018.7.1.6

[17] Bamford, J. (2017). Mobility as a Service: Where are we? Huddersfield: Huddersfield Business School for The Travelspirit foundation.

[18] Aaltonen, S. (2017). MaaS Readiness Level Indicators for local authorities. CIVITAS ECCENTRIC project.

[19] Lyons, G., Hammond, P., \& Mackay, K. (2019). The importance of user perspective in the evolution of MaaS. Transportation Research part A, 121, 22-36. https://doi.org/10.1016/j.tra.2018.12.010

[20] CityLab. (2018). Helsinki's MaaS App, Whim: Is It Really Mobility,s Great Hope? Retrieved from Citylab: citylab.com/perspective/2018/10/helsinkis-maas-app-whimis-it-really-mobilitys-great-hope/573841/ (March 19, 2019)

[21] Masabi. (n.d.). SaaS Ticketing for Public Transport. Retrieved from masabi.com (March 19, 2019)

[22] SkedGo. (n.d.). Shaping the global future of mobility and smart cities. Retrieved from skedgo.com (March 19, 2019)

[23] Moovel. (n.d.). Mobility-as-a Service pioneer moovel: 6.5 million users, growth rate of $69 \%$. Retrieved from https://www.moovel.com/en/news-resources/press/ mobility-as-a-service-pioneer-moovel-6-5-million-usersgrowth-rate-of-69 (March 19, 2019)

[24] Newmobility.news. (2017, May 19). Whim app combines all means of transport in Antwerp. Retrieved from https://newmobility.news/wp-content/uploads/2017/10/ whim5-e1506930783697-960x577.jpg (March 19, 2019)
[25] Digital Journal. (n.d.). Mobility as a Service Market 2018 Global Trends, Size, Key Players, Share, Future Perspective, Emerging Technologies, Competitive landscape and Analysis by Forecast to 2023. Retrieved from http://www.digitaljournal.com/pr/4061974 (03-20-2019)

[26] ABI Research. (2016, September 12). ABI Research Forecasts Global Mobility as a Service Revenues to Exceed $\$ 1$ Trillion by 2030. Retrieved from https://www.abiresearch.com/press/abi-research-forecastsglobal-mobility-service-rev/ (March 19, 2019)

[27] MaaS Alliance. (n.d.). The Mobility as a Service (MaaS) Alliance. Retrieved 03 19, 2019, from maas-alliance.eu

[28] König, D., Eckhardt, J., Aapaoja, A., Sochor, J., \& Karlsson, M. (2016). Deliverable 3: Business and operator models for MaaS. MAASiFiE project funded by CEDR.

[29] Smith, G., Sochor, J., \& Karlsson, M. (2018). Mobility as a Service: Development scenarios and implications for public transport. Research in Transportation Economics, 69, 592599. https://doi.org/10.1016/j.retrec.2018.04.001

[30] Giesecke, R., Surakka, T., \& Hakonen, M. (2016). Conceptualising Mobility as a Service - A User Centric View on Key Issues of Mobility Services. Eleventh International Conference on Ecological Vehicles and Renewable Energies (EVER 2016). Monte Carlo. https://doi.org/10.1109/EVER.2016.7476443

[31] Civitas City Networks - CIVINET. (n.d.). Project CIVITAS ELAN Zagreb. Retrieved from https://civinetslohr.eu/hr/multimedija/projekt-civitas-elan-zagreb/ (March 28, 2019)

[32] Eurostat. (n.d.). Passenger cars in the EU. Retrieved from ec.europa.eu/eurostat/statistics-explained/index.php/ Passenger cars in the EU (April 8, 2019)

[33] Brčić, D., Slavulj, M., Šojat, D., \& Jurak, J. (2018). The role of Smart Mobility in Smart Cities. Fifth International Conference on Road and Rail Infrastructure (CETRA 2018). Zadar. https://doi.org/10.5592/CO/CETRA.2018.812

[34] Zagrebački električni tramvaj - ZET. (n.d.). Usluge. Retrieved from http://www.zet.hr/usluge/7\#kategorija_11 (April 29, 2019)

[35] Matulin, M., Mrvelj, Š., \& Jelušić, N. (2011). Two-level Evaluation of Public Transport Performances. PROMET Traffic\&Transportation, 23(5), 329-339. https://doi.org/10.7307/ptt.v23i5.151

[36] Šipuš, D., \& Abramović, B. (2018). Tariffing in Integrated Passenger Transport Systems: A Literature Review. PrometTraffic \& Transportation, 30(6), 745-751. https://doi.org/10.7307/ptt.v30i6.2948

\section{Contact information:}

Marko SLAVULJ, PhD, Assistant Professor

(Corresponding author)

University of Zagreb, Faculty of Transport and Traffic Sciences,

Vukelićeva 4, HR-10000 Zagreb, Croatia

E-mail: mslavulj@fpz.hr

DubravkoTOMAŠıć, PhD, External Associate

University of Zagreb, Faculty of Transport and Traffic Sciences,

Vukelićeva 4, HR-10000 Zagreb, Croatia

E-mail: dtomasic@fpz.hr

Mario ĆosIĆ, PhD, Postdoctoral Researcher,

University of Zagreb, Faculty of Transport and Traffic Sciences,

Vukelićeva 4, HR-10000 Zagreb, Croatia

E-mail: mcosic@fpz.hr

Dino ŠOJAT, MSc, PhD Candidate,

University of Zagreb, Faculty of Transport and Traffic Sciences,

Vukelićeva 4, HR-10000 Zagreb, Croatia

E-mail: dsojat@fpz.hr 